University of New Hampshire

University of New Hampshire Scholars' Repository

$5-8-2012$

\title{
Linking goniometer measurements to hyperspectral and multi- sensor imagery for retrieval of beach properties and coastal characterization
}

\author{
Charles M. Bachmann \\ U.S. Naval Research Laboratory \\ Deric Gray \\ U.S. Naval Research Laboratory \\ Andrei Abelev \\ U.S. Naval Research Laboratory \\ William D. Philpot \\ Cornell University \\ Marcos J. Montes

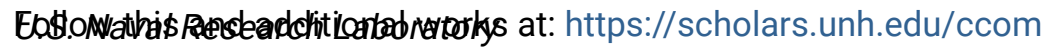 \\ Part of the Oceanography and Atmospheric Sciences and Meteorology Commons
}

See next page for additional authors

\section{Recommended Citation}

Charles M. Bachmann ; Deric Gray ; Andrei Abelev ; William Philpot ; Marcos J. Montes ; Robert Fusina ; Joseph Musser ; Rong-Rong Li ; Michael Vermillion ; Geoffrey Smith ; Daniel Korwan ; Charlotte Snow ; W. David Miller ; Joan Gardner ; Mark Sletten ; Georgi Georgiev ; Barry Truitt ; Marcus Killmon ; Jon Sellars ; Jason Woolard ; Christopher Parrish and Art Schwarzscild " Linking goniometer measurements to hyperspectral and multisensor imagery for retrieval of beach properties and coastal characterization ", Proc. SPIE 8390, Algorithms and Technologies for Multispectral, Hyperspectral, and Ultraspectral Imagery XVIII, 83901D (May 8, 2012); doi:10.1117/12.918464; http://dx.doi.org/10.1117/12.918464

This Conference Proceeding is brought to you for free and open access by the Center for Coastal and Ocean Mapping at University of New Hampshire Scholars' Repository. It has been accepted for inclusion in Center for Coastal and Ocean Mapping by an authorized administrator of University of New Hampshire Scholars' Repository. For more information, please contact Scholarly.Communication@unh.edu. 


\section{Authors}

Charles M. Bachmann, Deric Gray, Andrei Abelev, William D. Philpot, Marcos J. Montes, Robert A. Fusina, Joseph Musser, Rong-Rong Li, Michael Vermillion, Geoffrey Smith, Daniel Korwan, Charlotte Snow, David W. Miller, Joan Gardner, Matt Sletten, Georgi Georgiev, Barry Truitt, Marcus Kilmon, Jon Sellars, Jason Woolard, Christopher Parrish, and A. Schwarzschild 


\title{
Linking goniometer measurements to hyperspectral and multisensor imagery for retrieval of beach properties and coastal characterization
}

\author{
$*$ Charles M. Bachmann *Deric Gray ${ }^{\circ}$ Andrei Abelev $†$ William Philpot *Marcos J. Montes *Robert \\ Fusina $\ddagger$ Joseph Musser *Rong-Rong Li $\quad{ }^{\circ}$ Michael Vermillion *Geoffrey Smith *Daniel \\ Korwan $*^{*}$ Charlotte Snow ^W. David Miller ${ }^{\circ}$ Joan Gardner $\dagger \dagger$ Mark Sletten ${ }^{\circ}{ }^{\circ}$ Georgi Georgiev ${ }^{\wedge}$ Barry \\ Truitt $\wedge^{\wedge}$ Marcus Kil@on $* *$ Jon Sellars $* * J a s o n$ Woolard $* *$ Christopher Parrish $\$$ \$Art Schwarzschild \\ *U.S. Naval Research Laboratory, Coastal \& Ocean Remote Sensing Branch, Washington, D.C. 20375 \\ ${ }^{\circ}$ U.S. Naval Research Laboratory, Marine Physics Branch, Washington, D.C. 20375 \\ $\dagger \dagger$ U.S. Naval Research Laboratory, Image Science and Applications Branch, Washington, D.C. 20375 \\ $†$ Cornell University, School of Civil and Environmental Engineering, Ithaca, NY \\ $\ddagger$ Stephen F. Austin State University \\ George Mason University, Fairfax, VA \\ ${ }^{\wedge} \mathrm{CPI}$ \\ ${ }^{\circ}$ Sigma Space Corporation, Lanham, MD 20706 \\ $\wedge^{\wedge}$ The Nature Conservancy, Nassawaddox, VA \\ **NOAA NOS, Silver Spring, MD \\ $\$ \neq$ University of Virginia, Department of Environmental Sciences, Anheuser Busch Coastal Research \\ Center, Oyster, VA
}

\begin{abstract}
In June 2011, a multi-sensor airborne remote sensing campaign was flown at the Virginia Coast Reserve Long Term Ecological Research ${ }^{10}$ site with coordinated ground and water calibration and validation (cal/val) measurements. Remote sensing imagery acquired during the ten day exercise included hyperspectral imagery (CASI-1500), topographic LiDAR, and thermal infra-red imagery, all simultaneously from the same aircraft. Airborne synthetic aperture radar (SAR) data acquisition for a smaller subset of sites occurred in September 2011 (VCR'11). Focus areas for VCR'11 were properties of beaches and tidal flats and barrier island vegetation and, in the water column, shallow water bathymetry. On land, cal/val emphasized tidal flat and beach grain size distributions, density, moisture content, and other geotechnical properties such as shear and bearing strength (dynamic deflection modulus), which were related to hyperspectral BRDF measurements taken with the new NRL Goniometer for Outdoor Portable Hyperspectral Earth Reflectance (GOPHER). This builds on our earlier work at this site in 2007 related to beach properties ${ }^{3}$ and shallow water bathymetry ${ }^{2}$. A priority for VCR'11 was to collect and model relationships between hyperspectral imagery, acquired from the aircraft at a variety of different phase angles, and geotechnical properties of beaches and tidal flats. One aspect of this effort was a demonstration that sand density differences are observable and consistent in reflectance spectra from GOPHER data, in CASI hyperspectral imagery, as well as in hyperspectral goniometer measurements conducted in our laboratory after VCR'11.
\end{abstract}

Keywords: hyperspectral, goniometer, multi-sensor, remote sensing, bi-directional reflectance distribution function (BRDF), coast type, beaches, sand density, geotechnical, Virginia Coast Reserve

\footnotetext{
Algorithms and Technologies for Multispectral, Hyperspectral, and Ultraspectral Imagery XVIII, edited by Sylvia S. Shen, Paul E. Lewis, Proc. of SPIE Vol. 8390, 83901D · @ 2012 SPIE CCC code: $0277-786 X / 12 / \$ 18 \cdot$ doi: $10.1117 / 12.918464$
} 


\section{INTRODUCTION}

\subsection{Background on BRDF and Applications}

Measurement and modeling of BRDF have been described in many publications ${ }^{4,5,6,7,8,9}$. BRDF and, in particular, the shape of the hyperspectral reflectance about the retro-reflectance direction are closely related to important geophysical parameters such as grain size and density (for granular surfaces) $)^{5,6,7}$ and biophysical parameters such as biomass and leaf area index (LAI) for vegetation ${ }^{5,7,1}$.

\section{EXPERIMENT AND METHODS}

\subsection{BRDF and the VCR'11 Experiment}

The VCR'11 experiment was designed to address the significance of BRDF in modeling and retrieval of geotechnical parameters, including composition, grain size distributions, density, moisture content, and other geotechnical properties such as shear and bearing strength (dynamic deflection modulus). Airborne data collection during VCR'11 was designed to maximize acquisition from a large number of phase angles for each position on the ground or water. This experiment was a multi-sensor remote sensing study, which included airborne hyperspectral imaging, thermal imaging, topographic LiDAR, and polarimetric synthetic aperture radar (SAR). The HSI, thermal, and LiDAR sensors were all flown simultaneously on the same platform during cal/val activities on land and water, while L- and P-band SAR data were acquired 2 months later.

\subsection{BRDF Measurements Using GOPHER}

Of particular significance in this study was the use of a new NRL field-portable hyperspectral goniometer system known as the Goniometer for Outdoor Portable Hyperspectral Earth Reflectance (GOPHER), shown in Figure 1. GOPHER is configured with a Spectra Vista full-range (VNIR/SWIR) HR-1024 spectrometer, mounted on a zenith arc (quarter arc). The spectrometer is robotically controlled, moving freely in zenith along the arc, while the arc rotates freely in azimuth. The instrument scan pattern can be changed rapidly in the field on the controller laptop, and the arc is mounted on a mast, which can be raised or lowered to accommodate variable terrain.

During VCR'11, GOPHER BRDF measurements were acquired along transects on beaches and tidal flats on Hog Island, VA, part of the Virginia Coast Reserve Long Term Ecological Research (VCR LTER) ${ }^{10}$ site on Virginia's Eastern Shore. At each transect position, GOPHER measurements were followed by geotechnical measurements (Figure 1) of a variety of beach and sediment properties, including moisture, field density, grain size distribution (determined later in the lab), shear strength measured with a static cone penetrometer and with a dynamic cone penetrometer, dynamic deflection modulus measured with a light-weight deflectometer, as well as other related quantities. To monitor light levels during the course of the GOPHER scans, an Analytical Spectral Devices (ASD) spectrometer was also used to record radiance levels from a white Spectralon ${ }^{\mathrm{TM}}$ reference plaque throughout the measurement cycle. Each GOPHER scan also began with an initial calibration from a white plaque at nadir. The size of the GOPHER arc prevents a full scan of the white plaque in the field, however, this was accomplished in our NRL calibration laboratory to determine angular dependence of the radiance from the plaque observed by the SVC spectrometer that is integral to GOPHER. 


\section{Results}

\subsection{Density Effects Observable in Hyperspectral BRDF of Beaches}

The density of sands, powders, and sediments are known to parameterize $\mathrm{BRDF}^{5,7}$. Many of the papers published on this subject have focused on verification in laboratory studies using powders of a single consistent material. Beach sands are usually a composite of multiple materials, and the VCR LTER beaches are no exception. Although the sands are dominated by quartzite, other mineral fractions appear in these sands, and many of these are smaller and darker mineral components such as magnetite. These darker mineral fractions also tend to be composed of smaller grains compared with the dominant sands, although there is some overlap in their grain size distributions.

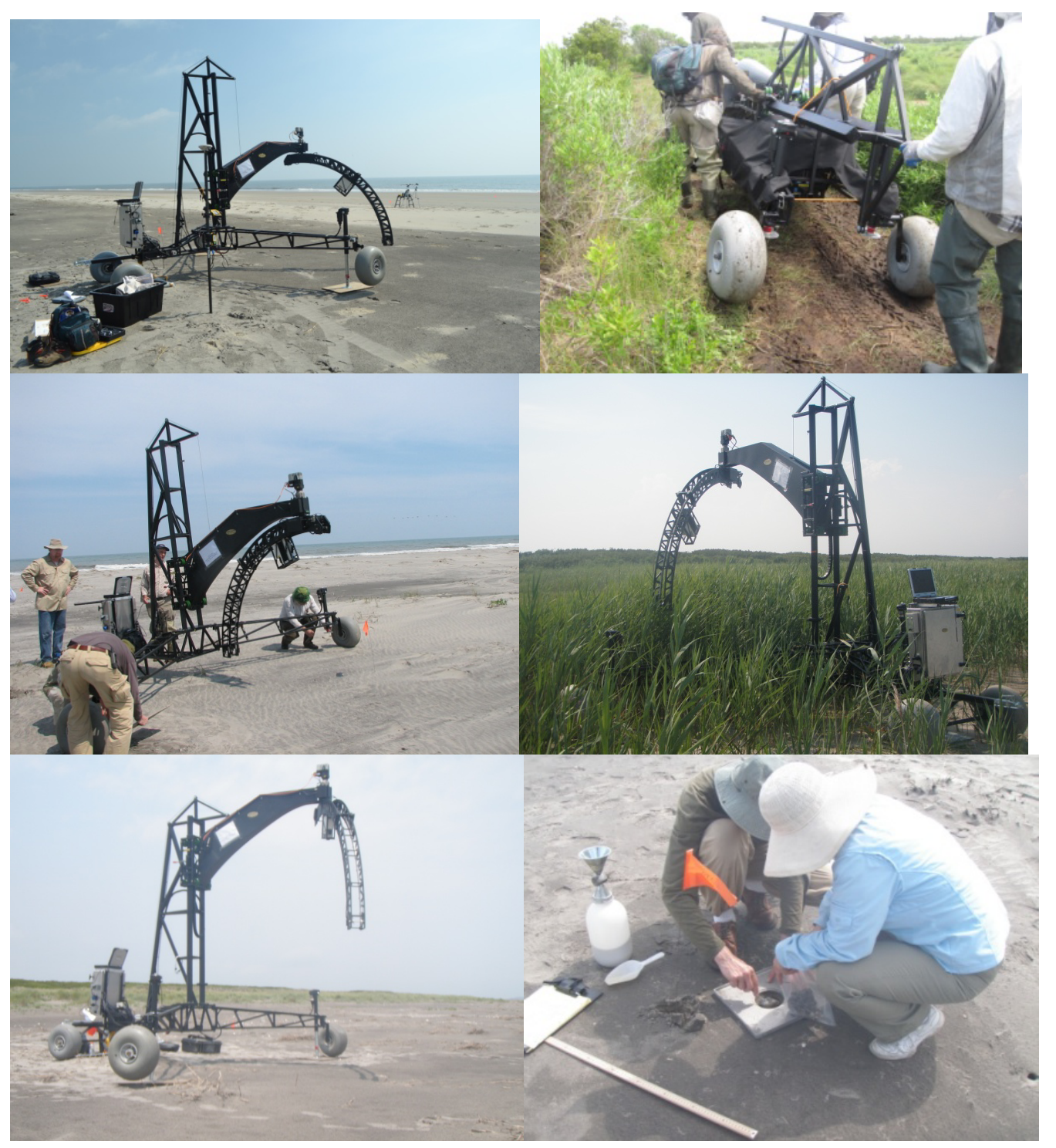

Figure 1. NRL Goniometer for Portable Hyperspectral Earth Reflectance (GOPHER): (top, left) GOPHER fully deployed at Hog Island, VA in June 2011; ASD monitoring Spectralon ${ }^{\mathrm{TM}}$ plaque in background. (Top, right) GOPHER is highly compact in transport mode and can be maneuvered manually or pulled behind an ATV; (middle, left) measurements at VCR'11 of sand BRDF and (middle, right) vegetation BRDF ; (bottom, left) the GOPHER zenith arc can be raised or lowered on a mast to accommodate variable terrain or vegetation canopy height. (Bottom, right) geotechnical measurements along the transect. 


\subsection{Hyperspectral BRDF measurements with a tabletop goniometer}

Following VCR'11, sand samples acquired by us were used in a series of laboratory tests to examine the effect of sand density on spectral reflectance. A tabletop goniometer was established on an optical bench in our NRL calibration laboratory and consisted of an ASD with 8 degree fore-optic mounted on a rotational stage and an ASD lamp mounted on a second rotational stage. The two stages were oriented to allow measurements in the principal plane (Figure 2). Figure 2 shows examples of reflectance curves for a set of wavelengths selected from the visible, near infra-red (NIR), and short-wave infra-red (SWIR). These curves of reflectance vs phase angle show that the lower density sands generally have a larger reflectance than the higher density sands. The effect appears to grow with increasing phase angle, and is strongest in the short-wave infra-red. If the sand were a single material, radiative transfer theory ${ }^{5,7}$ would predict that the higher density sands would have the larger reflectance, however, VCR LTER sands, as noted earlier, and observed in Figure 2, are composite materials. A conjecture is that the finer mineral fractions, which tend to be smaller in VCR sands, tend to fill the sand pores more completely when density increases, and as such are less likely to be shadowed. These sand grains tend to be very dark like those shown in Figure 2, and tend to absorb the downwelling irradiance more readily in this configuration. The result is that the higher density sands at the VCR tend to be less reflective, producing the results seen in Figure 2.

\subsection{Hyperspectral BRDF measurements with GOPHER}

GOPHER data taken in the field also confirms the same conclusions, as the example in Figure 3 illustrates. Figure 3 shows the reflectance versus phase angle for a SWIR wavelength derived from our data taken at two sites along one of our transects on the eastern shore of Hog Island, VA. Field density measurements were taken in conjunction with GOPHER measurements and site photos in the figure show the appearance of the sand at each location. The example in Figure 3 shows that the sand density differed by $\sim 10 \%$ between these two sites. As in the tabletop goniometer measurements, the GOPHER goniometer data in Figure 3 illustrates the fact that the higher density sands have lower reflectance.

The example in Figure 3 compared GOPHER data for two relatively dry regions of the beach where the moisture level was only $0.2 \%$. The effect, however, does not appear to be limited to dry sands. GOPHER transects encompassed a wide range of conditions, and the example in Figure 4, illustrates a case in which moisture levels were significantly higher. The sites in Figure 4 had comparable moisture levels with 22.9\% (position HT2-3) and 20.9\% (position HT2-5), but the field density differed by 15\%: 1.671 $\mathrm{gm} / \mathrm{cm}^{3}$ for HT2-3 vs $1.919 \mathrm{gm} / \mathrm{cm}^{3}$ for HT2-5. Figure 4 shows plots of reflectance vs phase angle at a red wavelength and a SWIR wavelength; as before, the higher density sands are again less reflective and the effect is strongest in the SWIR. 


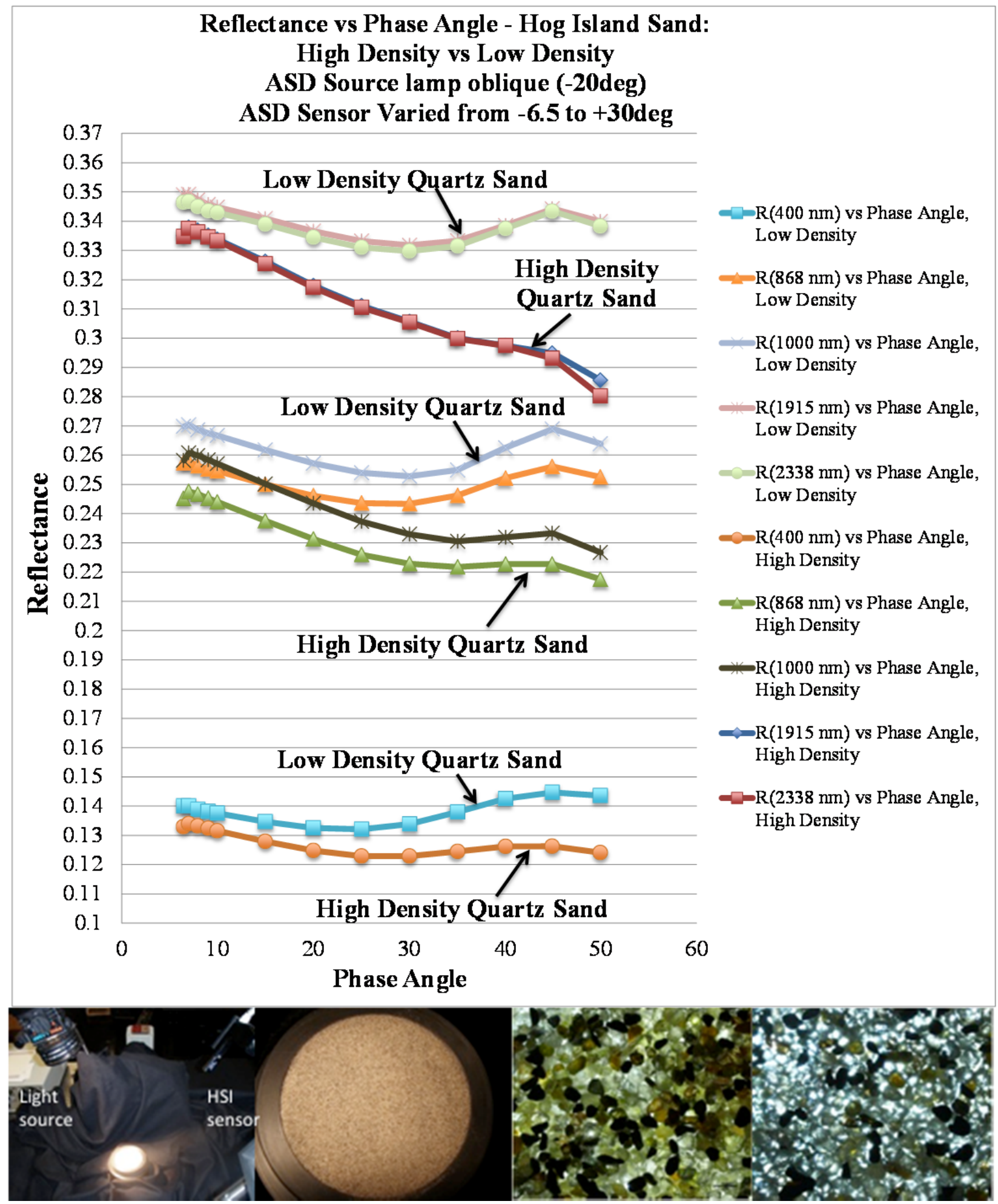

Figure 2. (Top) Hyperspectral reflectance varies in characteristic ways with phase angle depending on sand density. This can be exploited to estimate sand density from single- and multi-look HSI. (Bottom, left) Table-top goniometer configuration with ASD light source and spectrometer and sand sample in Delrin holder; (bottom, right) sand samples in higher (left) and lower density (right) cases imaged on slide. 


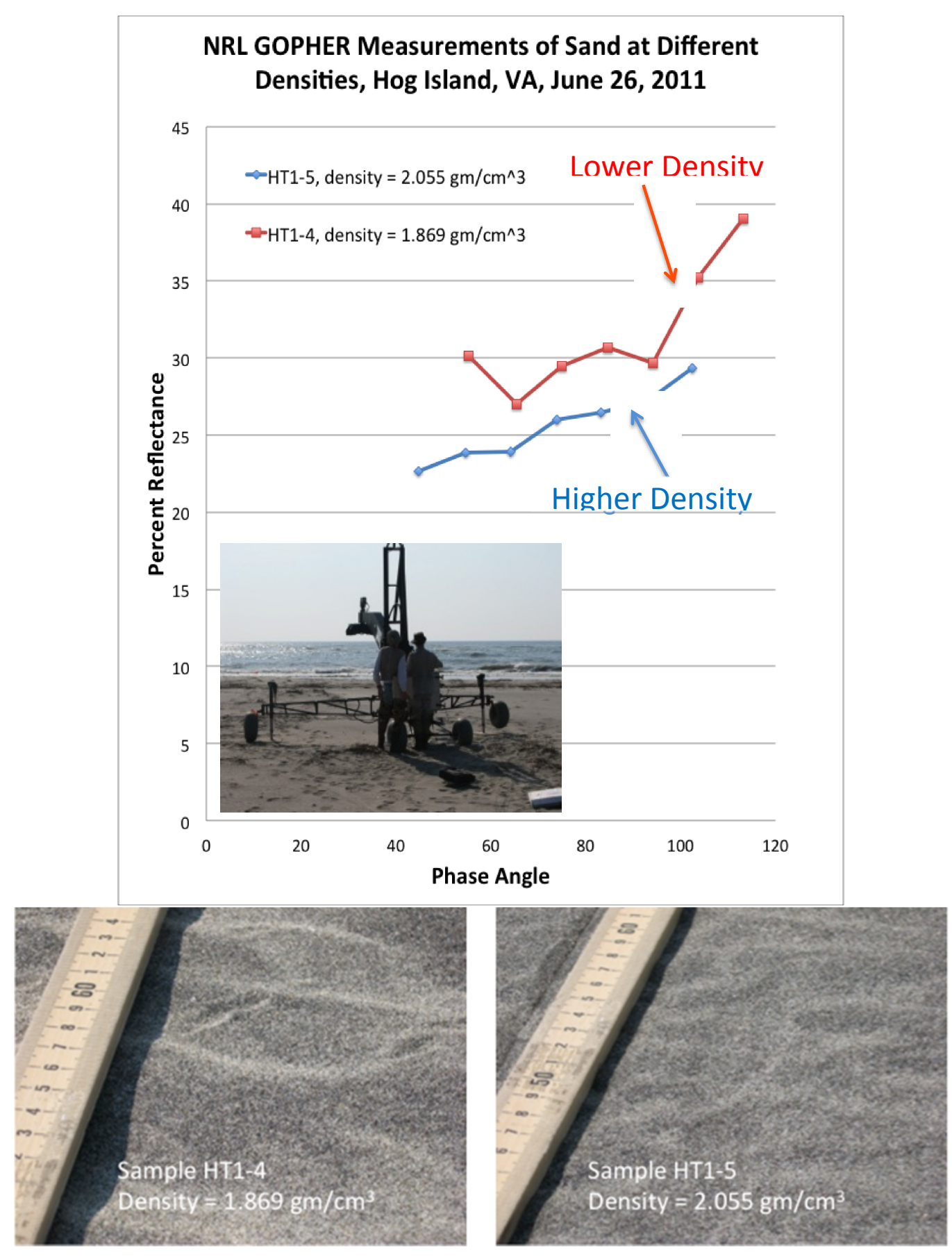

Figure 3. NRL GOPHER measurements of BRDF, Hog Island, VA. (Top) Comparison of higher and lower density sand regions with the same moisture level, showing the increased reflectance for the lower density sand at an example wavelength in the SWIR $(2338.1 \mathrm{~nm})$. Note the difference in reflectance is generally largest at the biggest phase angles. (Bottom) photo of the sand sample sites. Both sites had low moisture (0.2\%) but densities differed by about $10 \%$.

\subsection{CASI measurements at variable phase angles}

CASI-1500 hyperspectral imagery was acquired from our multi-sensor installation on board a twin otter aircraft over a ten day period in conjunction with the GOPHER and geotechnical field measurements. Flight lines were flown with significant overlap between adjacent lines along parallel headings. Headings were varied and oriented along several cardinal headings: into and out of the solar azimuth direction 
(generally preferred for water applications), perpendicular to the solar azimuth direction, and at oblique angles 45 degrees to the solar azimuth heading. Acquiring the data in this manner ensured variation in the phase angle. Likewise, flights were also undertaken at varying times of day along these headings to allow for further variations in phase angle.

Figure 5 illustrates the fact that the same sand density effects on reflectance are observable in the CASI1500 imagery. In particular, Figures 5 shows the effect is more pronounced at larger phase angles, consistent with what we observed in Figures 2-4 in both tabletop goniometer measurements as well as GOPHER measurements at the same locations shown for the CASI results.
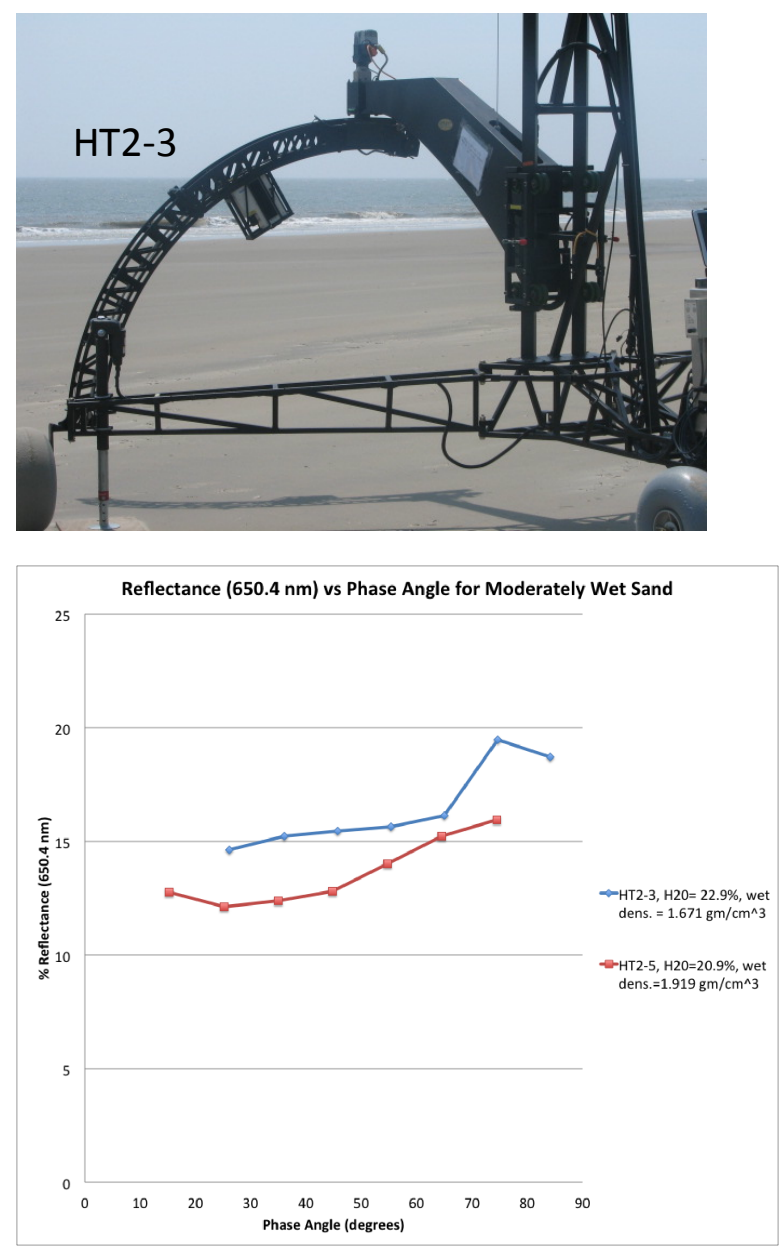
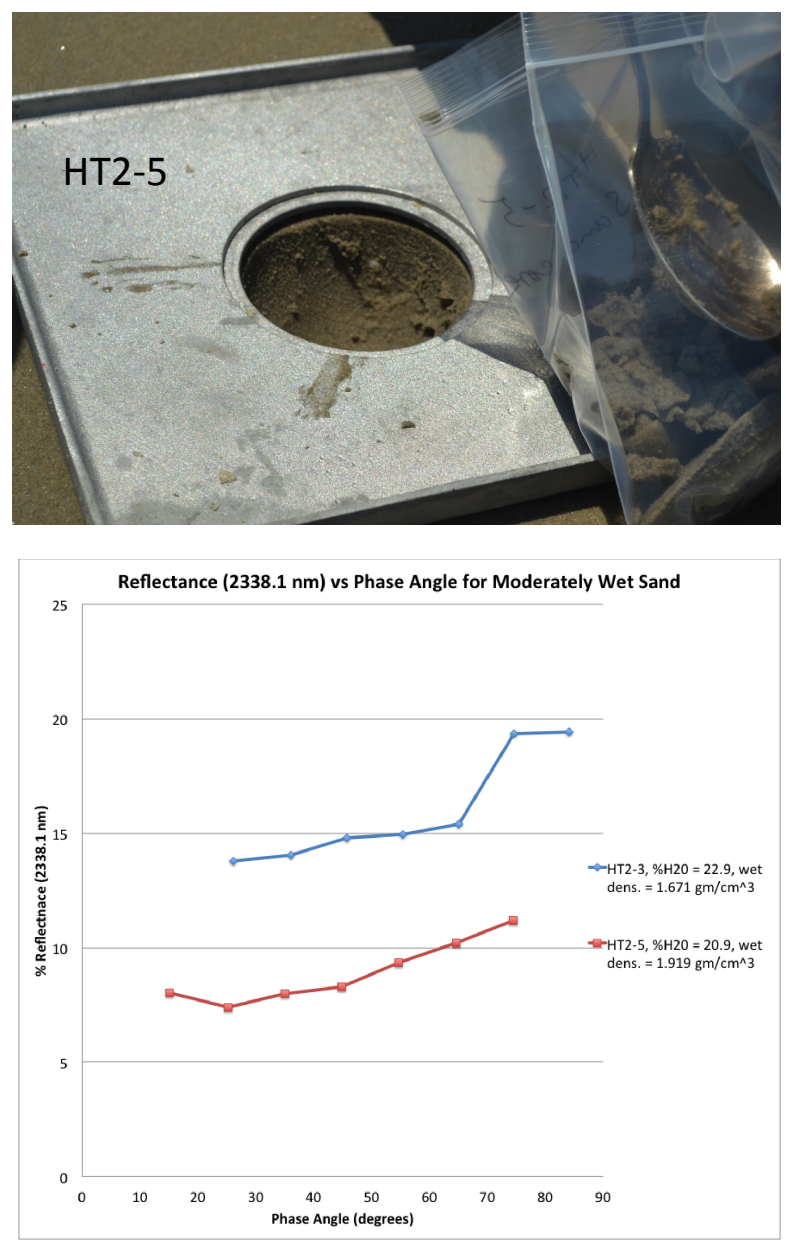

Figure 4. Comparison of two Hog Island field sites with higher and comparable moisture level, but different sand field densities. (Top, left) GOPHER measurement scan at site HT2-3 with moisture level $22.9 \%$ and field density of 1.671 $\mathrm{gm} / \mathrm{cm}^{3}$. (Top right) Geotechnical sampling at site HT2-5 with moisture level $20.9 \%$ and field density of $1.919 \mathrm{gm} / \mathrm{cm}^{3}$. (Bottom, left) Reflectance at a red wavelength $(650.4 \mathrm{~nm})$ vs phase angle for the higher and lower density sands, showing that the higher density sands have lower reflectance; (bottom right) similar plot for a short-wave infra-red wavelength $(2338.1 \mathrm{~nm})$, showing that the effect is strongest in the SWIR. 

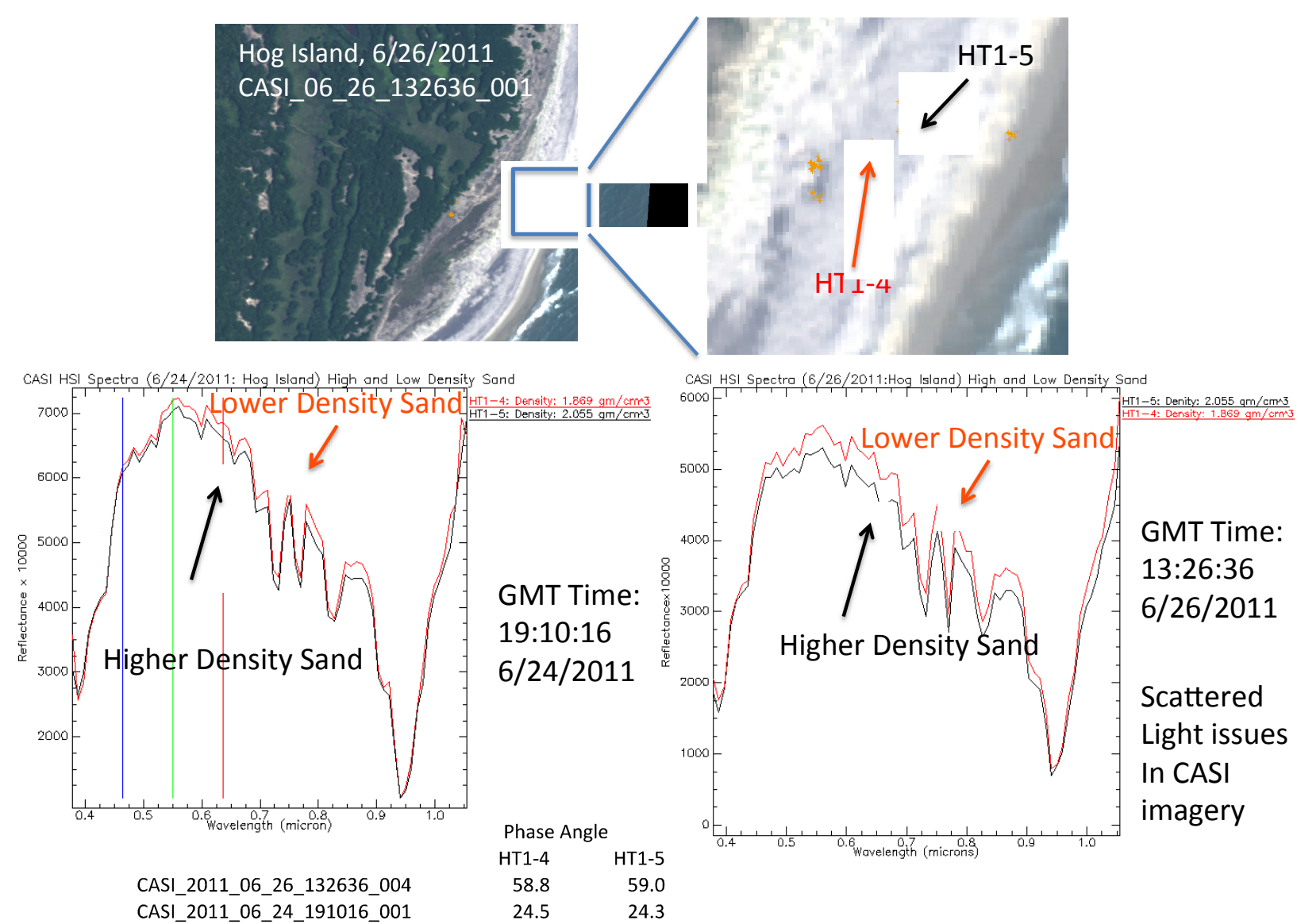

CASI_2011_06_26_132636_004

CASI_2011_06_24_191016_001

$24.5 \quad 24.3$

Figure 5. Sand density effects observable in CASI-1500 hyperspectral imagery of Hog Island, VA. (Top,left) A subset of a CASI scene on June 26, 2011. (Top right) Zoom window, showing position of GOPHER measurements on the beach. (Bottom) CASI reflectance spectra at position HT1-4 and HT1-5 (corresponding to GOPHER measurement shown in Figure 2) with phase angles listed for each scene. Note that the differences in reflectance due to density effects are more pronounced at larger phase angles, consistent with what is observed in our table-top goniometer and GOPHER measurements. CASI data showed effects of instrument scattered light beyond 0.9 microns, which have not been corrected in this example, so these regions should be ignored.

\section{SUMMARY AND CONCLUSIONS}

Remote sensing imagery acquired during a ten day exercise at the Virginia Coast Reserve included hyperspectral imagery (CASI), topographic LiDAR, and thermal infra-red imagery, all simultaneously from the same aircraft. Airborne synthetic aperture radar (SAR) data was acquired for a smaller subset of sites. VCR'11 emphasized properties of beaches and tidal flats, barrier island vegetation and shallow water bathymetry. On land, tidal flat and beach composition, grain size distributions, density, moisture content, and other geotechnical properties including shear strength and dynamic deflection modulus, were related to hyperspectral BRDF measurements taken with the new NRL Goniometer for Outdoor Portable Hyperspectral Earth Reflectance (GOPHER). In this paper, we emphasized the observable effects of sand density variations within hyperspectral reflectance data as phase angle is varied. Analysis of reflectance vs phase angle showed consistency between laboratory goniometer measurements of hyperspectral BRDF, GOPHER hyperspectral BRDF, and CASI imagery acquired at different phase angles for the same field sites on the ground. The results showed that significant differences between low and high density sand are observable in the tabletop goniometer, the GOPHER field goniometer, and the CASI imagery, 
and that in particular higher density sands at our measurement site at Hog Island, VA at the VCR LTER site tended to be less reflective than the lower density sands. This is contrary to what would be expected from radiative transfer theory if the sand were a single uniform material. We conjectured that this result is due to the presence of a smaller and very dark mineral fraction consisting of magnetite and other minerals. In higher density sands these darker and smaller mineral fractions will tend to fill the pores within the sand matrix dominated by lighter quartzite, and will be less shadowed in this configuration, making the sand less reflective because these darker mineral fractions absorb more incident light. It should be noted that the results of density effects on BRDF should be expected to vary with coast type, and in particular with the composition of sands and sediments within particular coast types. Thus, these results should be interpreted as being applicable to the sands of the VCR LTER barrier island coast type, and to areas similar to this coast type in other locations.

\section{References}

[1] Asrar, G. (ed.), Theory and Applications of Optical Remote Sensing, New York, New York: John Wiley \& Sons, (1989).

[2] Bachmann, C. M., M. J. Montes, R. A. Fusina, C. Parrish, J. Sellars, A Weidemann, W. Goode, C. R. Nichols, P. Woodward, K. McIlhany, V. Hill, R. Zimmerman, D. Korwan, B Truitt, A. Schwarzschild, "Bathymetry Retrieval from Hyperspectral Imagery in the Very Shallow Water Limit: a Case Study from the 2007 Virginia Coast Reserve (VCR ’07) Multi-sensor Campaign,” 2010. Marine Geodesy, 33:53-75.

[3] Bachmann, C. M., C. R. Nichols, M. Montes, R. Li, P. Woodward, R. A. Fusina, W. Chen, V. Mishra, W. Kim, J. Monty, K. McIlhany, K. Kessler, D. Korwan, D. Miller, E. Bennert, G. Smith, D. Gillis, J. Sellers, C. Parrish, A. Schwarzschild, B. Truitt, 2010. "Retrieval of Substrate Bearing Strength from Hyperspectral Imagery During the Virginia Coast Reserve (VCR ’07) Multi-Sensor Campaign,” Marine Geodesy, 33(2-3): 101-116.

[4] Georgiev, G., C. Gatebe, J. Butler and M. King, "BRDF Analysis of Savanna Vegetation and Salt-Pan Samples," IEEE Trans. Geosci. Remote Sens., vol. 47, pp. 2546-2556, (2009).

[5] Hapke,B., Theory of Reflectance and Emittance Spectroscopy, Cambridge, England: Cambridge University Press, (1993)

[6] Hapke, B., "Bidirectional reflectance spectroscopy - 6. Effects of porosity," Icarus, vol. 195, pp. 918-926, Jun, (2008).

[7] Hapke, B., Theory of Reflectance and Emittance Spectroscopy, Second Edition. Cambridge, England: Cambridge University Press, (2012)

[8] Helfenstein, P. and M. K. Shepard, "Testing the Hapke photometric model: Improved inversion and the porosity correction," Icarus, vol. 215, pp. 83-100, 9, 2011.

[9] Mischenko, M. I., J. M. Dlugach, E. G. Yanovitskij, N. T. Zakharova, "Bidirectional reflectance of flat, optically thick particulate layers: an efficient radiative transfer solution and applications to snow and soil surfaces, Journal of Quantitative Spectroscopy, vol. 63, pp. 409-432, (1999).

[10] http://www.vcrlter.virginia.edu/home1/index.php 